\title{
Mesoporous Zirconia Coating for Sensing Applications Using Attenuated Total Reflection Fourier Transform Infrared (ATR FT-IR) Spectroscopy
}

\author{
Dominik Wacht ${ }^{1}$, Mauro David ${ }^{2}$, Borislav Hinkov ${ }^{2}$, Hermann Detz ${ }^{2,3}$, Andreas \\ Schwaighofer ${ }^{1}$, Bettina Baumgartner ${ }^{1}$ and Bernhard Lend $1^{1 *}$
}

${ }^{1}$ Research Division of Environmental Analytics, Process Analytics and Sensors, Institute of Chemical Technologies and Analytics, Technische Universität Wien, Getreidemarkt 9, 1060 Vienna, Austria

${ }^{2}$ Institute of Solid-State Electronics \& Center for Micro- and Nanostructures, Technische Universität Wien, Gußhausstraße 25, 1040 Vienna, Austria

${ }^{3}$ Central European Institute of Technology, Brno University of Technology, Brno, Czech Republic

*E-mail: bernhard.lendl@tuwien.ac.at

(C) 2021. The Authors. Reuse is restricted to non-commercial and no derivative uses.

This is the accepted version of the following article: D. Wacht, M. David, B. Hinkov, H. Detz, A.Schwaighofer,

B. Baumgartner, B. Lendl. "Mesoporous Zirconia Coating for Sensing Applications using Attenuated Total Reflection Fourier Transform Infrared Spectroscopy”. Applied Spectroscopy. Special Issue: Honoring Peter Griffiths., which has been published in final form at https://doi.org/10.1177/00037028211057156. 


\begin{abstract}
Mid-infrared attenuated total reflection (ATR) spectroscopy is a powerful tool for in situ monitoring of various processes. Mesoporous silica, an extensively studied material, has already been applied in sensing schemes due to its high surface area and tunable surface chemistry. However, its poor chemical stability in aqueous solutions at $\mathrm{pH}$ values higher than 8 and strong absorption below $1250 \mathrm{~cm}^{-1}$ limits its range of applications. To circumvent these problems, a mesoporous zirconia coating on ATR crystals was developed. Herein, the synthesis, surface modification, and characterization of ordered mesoporous zirconia films on $\mathrm{Si}$ wafers and Si-ATR crystals are presented. The modified coating was applied in sensing schemes using aromatic and aliphatic nitriles in aqueous solution as organic pollutants. The mesoporous zirconia coating shows strong chemical resistance when kept in alkaline solution for $72 \mathrm{~h}$. The success of surface modification is confirmed using Fourier transform infrared (FT-IR) spectroscopy and contact angle measurements. Benzonitrile and valeronitrile in water are used as model analytes to evaluate the enrichment performance of the film. The experimental results are fitted using Freundlich isotherms, and enrichment factors of 162 and 26 are calculated for $10 \mathrm{mg} \mathrm{L}^{-1}$ benzonitrile and $25 \mathrm{mg} \mathrm{L}^{-1}$ valeronitrile in water, respectively. Limits of detection of $1 \mathrm{mg} \mathrm{L}^{-1}$ for benzonitrile and $11 \mathrm{mg} \mathrm{L}^{-1}$ for valeronitrile are obtained. The high chemical stability of this coating allows application in diverse fields such as catalysis with the possibility of in situ monitoring via FT-IR spectroscopy.
\end{abstract}

Keywords: porous materials, infrared spectroscopy, functional coatings, sensor, thin film 


\section{Introduction}

In typical attenuated total reflection Fourier transform infrared (ATR FT-IR) sensing schemes, claddings are used to increase selectivity and sensitivity by enriching the analyte in the probed volume of the evanescent field. Furthermore, these coatings can introduce additional benefits, for instance hydrophobicity to exclude water, as seen in Fig. 1. Thereby the strong background absorption of water is reduced, which allows to increase the number of total reflections also contributing to an increased sensitivity. This concept has been proven on attenuated total reflection (ATR) crystals and optical fibers coated with polymers, ${ }^{1-7}$ zeolites, ${ }^{8,9}$ metal oxides, ${ }^{10}$ sol-gels, ${ }^{11}$ and mesoporous silica ${ }^{12-14}$ to detect volatile organic compounds in the gas or aqueous phase. Mesoporous materials show advantageous properties for sensing applications, such as large surface areas, adjustable porosity and pore size distribution, and ample possibilities for chemical surface modifications allowing to discriminate different analytes according to their size, polarity, or functionality. ${ }^{15-20}$.

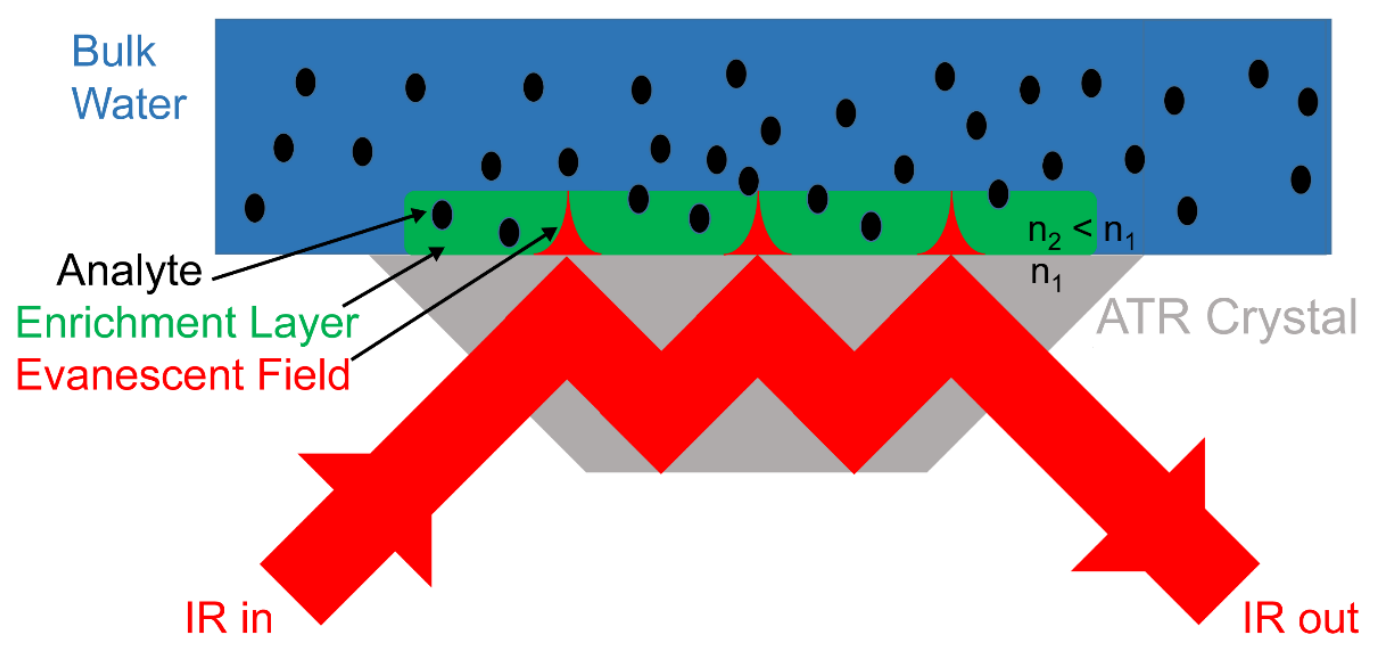

Figure 1. ATR-FTIR sensing scheme using enrichment layers.

Mesoporous silica $\left(\mathrm{SiO}_{2}\right)$ has been widely applied in sensing schemes; however, its application is limited by its chemical stability in aqueous solutions at $\mathrm{pH}$ values above eight. ${ }^{21-23}$ Furthermore, the strong absorption below $1250 \mathrm{~cm}^{-1}$ of the $\mathrm{SiO}_{2}$ network prevents analysis of various organic and inorganic sulfur- and phosphorus-containing compounds, such as sulfates and phosphates. ${ }^{24}$ Zirconia $\left(\mathrm{ZrO}_{2}\right)$ shows spectral transmittance in the fingerprint region until $1100 \mathrm{~cm}^{-1}$, high thermal, mechanical, and chemical stability and is therefore already widely applied in the field of chromatography, ${ }^{25,26}$ but its application as enrichment layer is yet pending. 
In this work, we demonstrate the first application of an ordered mesoporous $\mathrm{ZrO}_{2}$ coating in sensing applications using ATR FT-IR spectroscopy. We present the synthesis and the surface modification of a mesoporous $\mathrm{ZrO}_{2}$ coating as well as its characterization via FT-IR spectroscopy, X-ray diffraction (XRD), grazing-incidence small-angle scattering (GI-SAXS), and contact angle measurements. $\mathrm{ZrO}_{2}$ coatings were prepared by spin coating a precursor solution onto Si wafers or prepared rectangular Si-ATR crystals $\left(20 \times 10 \times 0.5 \mathrm{~mm}^{3}\right)$. After aging and calcination, the coating was functionalized using silanes. In enrichment studies, benzonitrile and valeronitrile were chosen as model analytes for aromatic and aliphatic compounds, as the obtained results can be benchmarked against findings from a previous study employing mesoporous silica films with the same analytes. ${ }^{13}$ The experimental data was fitted using Freundlich and Langmuir isotherms, and the adsorbed amount of analyte, the response time as well as the limits-of-detections were quantified.

\section{Experimental}

\section{Reagents and Materials}

Acetone (VWR, HiPerSolv CHROMANORM ${ }^{\circledR}$ for high-performance liquid chromatography (HPLC), $\geq 99.8 \%$ ), benzonitrile $\left(\mathrm{C}_{6} \mathrm{H}_{5} \mathrm{CN}\right.$, Sigma-Aldrich, 99\%), cetyltrimethylammonium bromide (CTAB, Sigma-Aldrich, 99\%), chloroform $\left(\mathrm{CHCl}_{3}\right.$, VWR, anhydrous $\geq 99.5 \%$ stabilized with iso-amylene, AnalaR NORMAPUR ${ }^{\circledR}$ analytical reagent), ethanol (EtOH, Chem-Lab, 100\% p.a.), hydrochloric acid (HCl, VWR, 37\%), Pluronic ${ }^{\circledR}$ F-127 (F-127, SigmaAldrich, BioReagent), tetraethoxysilane (TEOS, Sigma-Aldrich, 99.5\%), trichloro(phenyl)silane (TCI, $\geq 98.0 \%)$, valeronitrile $\left(\mathrm{C}_{4} \mathrm{H}_{9} \mathrm{CN}\right.$, Sigma-Aldrich, 99\%), zirconium(IV) propoxide $\left(\mathrm{Zr}(\mathrm{OPr})_{4}\right.$, AcroSealTM, ACROS OrganicsTM, $70 \mathrm{wt} \%$ in 1propanol).

\section{Synthesis of Mesoporous Zirconia}

The synthesis was adapted from literature. ${ }^{27}$ First, 0.72 g F-127 Pluronic ${ }^{\circledR}$ was suspended in $12.4 \mathrm{~g}(15.7 \mathrm{~mL})$ absolute $\mathrm{EtOH}$ and $1.5 \mathrm{~mL}$ conc. $\mathrm{HCl}$ was added under stirring. After completely dissolving the surfactant, $3.2 \mathrm{~g}(3.4 \mathrm{~mL})$ of a $70 \mathrm{wt} \% \mathrm{Zr}(\mathrm{OPr})_{4}$ in 1-propanol was added dropwise under vigorous stirring. This resulted in a final molar ratio of $1.0: 0.0075: 2.4$ : 35.2 : 2.4 for $\mathrm{Zr}(\mathrm{OPr})_{4}: \mathrm{F}-127: \mathrm{HCl}: \mathrm{EtOH}: \mathrm{PrOH}$. The obtained solution was stirred for $3 \mathrm{~h}$ at ambient temperature. The substrates used for spin coating were ultrasonically cleaned in EtOH for $15 \mathrm{~min}$. The relative humidity of the spin coater chamber was adjusted to $50 \%$ and 
approximately $50 \mu \mathrm{L}$ of this solution was spin coated onto Si wafers or Si ATR crystals at $2000 \mathrm{rpm}$ for $30 \mathrm{~s}$. After spin coating, the samples were aged for $2 \mathrm{~h}$ at ambient temperature, $1 \mathrm{~d}$ at $60^{\circ} \mathrm{C}$ and at $110^{\circ} \mathrm{C}, 150{ }^{\circ} \mathrm{C}$, and $185^{\circ} \mathrm{C}$ for $2 \mathrm{~d}$ each. After aging, the FT-IR spectra of $\mathrm{ZrO}_{2}$-coated Si-ATR crystals showed bands associated with the surfactant F-127 (Fig. S3, Supplemental Material). Removal of the surfactant by solvent extraction caused damage to the coating, so the surfactant was removed via calcination instead. Then, they were calcined at 500 ${ }^{\circ} \mathrm{C}$ with a heat ramp of $1{ }^{\circ} \mathrm{C} \mathrm{min}^{-1}$.

\section{Surface Modification of Mesoporous Zirconia}

The functionalization was adapted from the literature. ${ }^{28,29}$ The $\mathrm{ZrO}_{2}$-coated Si ATR crystals were ultrasonically cleaned in acetone, EtOH, and deionized water for $10 \mathrm{~min}$ each. After purging the sample with dry air, the coating was pre-treated at $110^{\circ} \mathrm{C}$ for approximately $12 \mathrm{~h}$. Then, it was placed in a three-neck round-bottom flask with a reflux condenser and bubbler, $\mathrm{N}_{2}$ inlet, and a vacuum connection. The coating was dried in vacuo at $150{ }^{\circ} \mathrm{C}$ for $2 \mathrm{~h}$. After purging the flask with $\mathrm{N}_{2}, 20 \mathrm{~mL}$ of $\mathrm{CHCl}_{3}$ and $400 \mu \mathrm{L}$ of trichloro(phenyl)silane were added at ambient temperature. The reaction mixture was kept in inert atmosphere for $24 \mathrm{~h}$. Then, the solution was removed and the $\mathrm{ZrO}_{2}$ coating was ultrasonically cleaned in acetone, EtOH, and deionized water for $10 \mathrm{~min}$ each. After purging the sample with dry air, the coating was placed in the oven at $90^{\circ} \mathrm{C}$ for approximately $12 \mathrm{~h}$.

\section{Synthesis of Mesoporous Silica}

The mesoporous $\mathrm{SiO}_{2}$ coating was synthesized as previously reported. ${ }^{13,30}$ A sol was prepared by diluting $2.08 \mathrm{~g}$ TEOS with $2.2 \mathrm{~mL}$ of EtOH and adding $0.9 \mathrm{~mL}$ of a $0.056 \mathrm{M}$ solution of $\mathrm{HCl}$ in $\mathrm{H}_{2} \mathrm{O}$. The mixture was stirred for $3 \mathrm{~h}$ at $40{ }^{\circ} \mathrm{C}$. Then, $0.041 \mathrm{~g}$ CTAB was dissolved in $0.5 \mathrm{~mL}$ EtOH, $0.5 \mathrm{~mL}$ of the reaction solution added, and the solution was stirred for $5 \mathrm{~min}$. The solution was spin coated at $2000 \mathrm{rpm}$ for $30 \mathrm{~s}$ at a relative humidity of $50 \%$ onto a $\mathrm{Si}$ substrate, which was ultrasonically cleaned in $\mathrm{EtOH}$ for 15 min prior to deposition. Afterwards, the coated substrate was pre-treated at $110{ }^{\circ} \mathrm{C}$ overnight, cooled to ambient temperature, followed by calcination at $400{ }^{\circ} \mathrm{C}$ for $5 \mathrm{~h}$ with a heating ramp of $1{ }^{\circ} \mathrm{C} \mathrm{min}^{-1}$.

\section{Fourier Transform Infrared Spectroscopy}

The FT-IR spectra were collected using a Vertex 80v spectrometer (Bruker Optics) operated with OPUS 7.5 software. A mercury-cadmium-telluride detector cooled with liquid nitrogen was used. All IR spectra were collected with a mirror speed of $80 \mathrm{kHz}$, a spectral resolution of 
$4 \mathrm{~cm}^{-1}$ and a total of 64 scans (measurement time: $14.9 \mathrm{~s}$ ) except for the IR spectra of enrichment studies, where 16 scans were averaged for each spectrum (measurement time: 3.75 s). Scans were obtained in double-sided, backward-forward acquisition mode. The aperture was set to $6 \mathrm{~mm}$ to obtain the best signal-to-noise ratio. Throughout measurements, the interferometer compartment was evacuated, while the sample compartment was continuously flushed with dry air. For the enrichment studies, the computed absorbance spectra were converted to ascii files in OPUS and evaluated using MATLAB R2020a, including baseline subtraction as well as integration of the IR bands.

\section{Methodology for Thin Film Characterization}

Optical Setup. Double-sided polished $10 \mathrm{~mm} \times 20 \mathrm{~mm} \times \sim 525 \mu \mathrm{m}$ Si wafers were provided by the IMEC/Ghent University. The wafers were glued to an aluminum holder with a defined angle of $45^{\circ}$ using wax. Then, the facets were polished using $\mathrm{Al}_{2} \mathrm{O}_{3}$ with a grain size of 30 and $9 \mu \mathrm{m}$ followed by diamond polishing with a grain size of $3 \mu \mathrm{m}, 1 \mu \mathrm{m}$, and $0.1 \mu \mathrm{m}$.

A home-built ATR mount and an aluminum flow cell were used for ATR FT-IR measurements. ${ }^{13,31}$ A stainless steel tubing (1/16", $0.75 \mathrm{~mm}$ I.D.) inlet was attached to the flow cell as well as a PTFE tubing (1/16", 0.75 mm I.D.) outlet. Liquids were transported using a peristaltic pump (Ismatec)

Microscopy. Microscopic images were taken using a Hyperion 3000 FTIR microscope (Bruker Optics)

X-ray Diffraction. X-ray diffraction patterns were collected using an X'Pert Pro diffractometer and Data Collector software by PANalytical (Almelo). This instrument was equipped with a $\mathrm{Cu}$ anode, whereby a voltage of $45 \mathrm{kV}$ and a current of $40 \mathrm{~mA}$ were applied, resulting in a wavelength of $1.54 \AA$. Bragg-Brentano geometry was used with 0.04 rad Soller slits and a divergence slit of $14^{\circ}$ as well as an anti-scatter slit of $1^{\circ}$ in the incident beam path. An anti-scatter slit of $5.0 \mathrm{~mm}$ was used in the diffracted beam path and an X'Celerator detector. XRD patterns were recorded at ambient temperature between $1^{\circ}$ and $6^{\circ}$ with a step size of $0.01^{\circ}$ and a counting time of $60 \mathrm{~s}$ at each step. The sample holder was rotated with a rotation time of 4 s. Evaluation of the wide-angle XRD patterns was performed using HighScore Plus software by PANalytical (Almelo). Non-ambient XRD measurements were conducted using an Empyrean multipurpose diffractometer and Data Collector software by PANalytical (Almelo) equipped with an HTK-1200N chamber (Anton Paar). Samples were placed in the chamber on the ceramic sample holder and fixed with a thermal paste. The same configurations as mentioned for XRD patterns were used for the measurement. 
The GI-SAXS measurements were conducted using an Empyrean multipurpose diffractometer and Data Collector software by PANalytical (Almelo, Netherlands) equipped with a $\mathrm{Cu}$ anode, where a voltage of $45 \mathrm{kV}$ and a current of $40 \mathrm{~mA}$ were applied, resulting in a wavelength of $1.54 \AA$ A. A focusing X-ray mirror, a divergence slit of $1 / 32^{\circ}$, and a GaliPIX3D detector were used. The measurement was conducted as described by PANalytical's guidelines. The collected diffraction patterns were evaluated using XRD2DScan software by PANalytical (Almelo).

Contact Angle Measurements. The measurements were performed using a drop shape analyzer 30 (Krüss) in combination with the provided ADVANCE 1.5.1.0 software. The device was equipped with a charged-coupled device camera. Static contact angles were determined by placing a $3 \mu \mathrm{L}$ drop of water on the sample's surface. Data analysis was performed by the Young-Laplace method within the instrument software.

Profilometry. Film thickness was determined using a DektakXT® profilometer with Vision64 software (Bruker). The coating was scratched using a pincer after spin coating. The obtained data was analyzed using the Data Analyzer of the software.

Ellipsometry. The refractive index of $\mathrm{ZrO}$ in the mid-IR region was obtained using a mid-IR ellipsometer (IR-VASE, J.A. Wollam) equipped with a thermal broadband source, a deuterated triglycin sulfate detector and a FT-IR spectrometer at a resolution of $2 \mathrm{~cm}^{-1}$. A reference scan on a bare Si substrate, cleaved from the same wafer as the sample, was recorded and fitted using a model for Si including Drude absorption due to free carriers. These parameters were consequently applied to fit the spectra of a $\mathrm{Si} / \mathrm{ZrO}$ layer stack, using an isotropic bulk model for $\mathrm{ZrO}$ with a filling factor of unity.

\section{Results and Discussion}

\section{Characterization of Mesoporous Zirconia}

Temperature stability studies of the mesostructure were performed after the aging process to determine the optimal calcination temperature for surfactant removal from the coating and further increased stability. To this purpose, $\mathrm{ZrO}_{2}$-coated $\mathrm{Si}$ wafer was heated to $900{ }^{\circ} \mathrm{C}$, during which XRD patterns were collected every $5{ }^{\circ} \mathrm{C}$. Upon increasing the temperature, the diffraction peak decreases in intensity and shifts to higher diffraction angles (2 $\theta)$, indicating a contraction of the structure (Fig. 2a). A local maximum is reached at $600{ }^{\circ} \mathrm{C}$, and at $900{ }^{\circ} \mathrm{C}$ there is still a diffraction peak discernible, whose intensity increases upon cooling to $25{ }^{\circ} \mathrm{C}$. The decrease in mesoporous ordering can be explained by recrystallization processes, which is 
evident from the wide-angle XRD patterns in Fig. 2b. After increasing the temperature to 900 ${ }^{\circ} \mathrm{C}$, broad diffraction peaks associated with a cubic or tetragonal $\mathrm{ZrO}_{2}$ structure become visible. Calcination of the mesoporous $\mathrm{ZrO}_{2}$ coating was performed at $500{ }^{\circ} \mathrm{C}$ with a heating ramp of $1{ }^{\circ} \mathrm{C} \min ^{-1}$. Small-angle XRD patterns show the presence of a cubic mesostructured (see Figs3a and $3 \mathrm{~b}$ ), while wide-angle XRD indicate no diffraction peaks associated with recrystallization
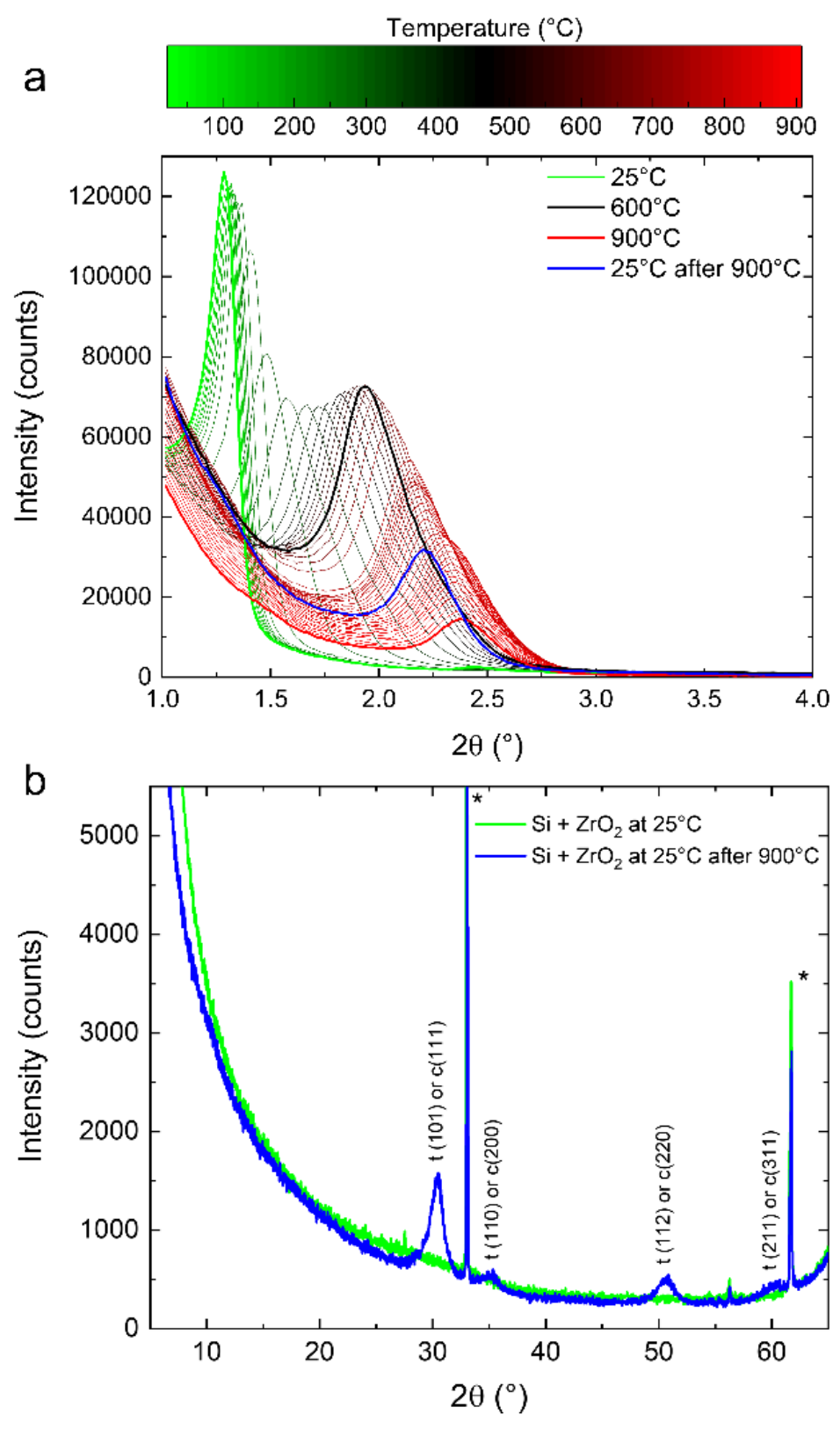

*...Si-wafer c...cubic $\mathrm{ZrO}_{2} \quad$ t...tetragonal $\mathrm{ZrO}_{2}$

Figure 2. (a) XRD patterns of a mesoporous $\mathrm{ZrO}_{2}$ coating on a $\mathrm{Si}$ wafer from $25{ }^{\circ} \mathrm{C}$ to $900{ }^{\circ} \mathrm{C}$ with emphasis on the measurements at $25^{\circ} \mathrm{C}, 600{ }^{\circ} \mathrm{C}$, and $900{ }^{\circ} \mathrm{C}$ and at $25^{\circ} \mathrm{C}$ after heating to $900{ }^{\circ} \mathrm{C}$. (b) Wide-angle XRD patterns of the same coating prior to the temperature treatment and at $25^{\circ} \mathrm{C}$ after heating to $900{ }^{\circ} \mathrm{C}$. 
and thus potential pore collapsing (see Fig. S4). Film thicknesses of $365 \pm 5.9 \mathrm{~nm}$ before and $237 \pm 11.4 \mathrm{~nm}$ after calcination were measured for the $\mathrm{ZrO}_{2}$ coating, which corresponds to a film contraction to $65 \%$ of the initial film thickness. The FT-IR absorbance spectra of $\mathrm{ZrO}_{2}$ on a Si ATR crystal before and after calcination are displayed in Figure 3c. The removal of the surfactant after calcination is evident from the absence of C-H stretching vibrations at 2966 $\mathrm{cm}^{-1}$ and $\mathrm{C}-\mathrm{H}$ bending vibrations between 1200 and $1500 \mathrm{~cm}^{-1}{ }^{24}$
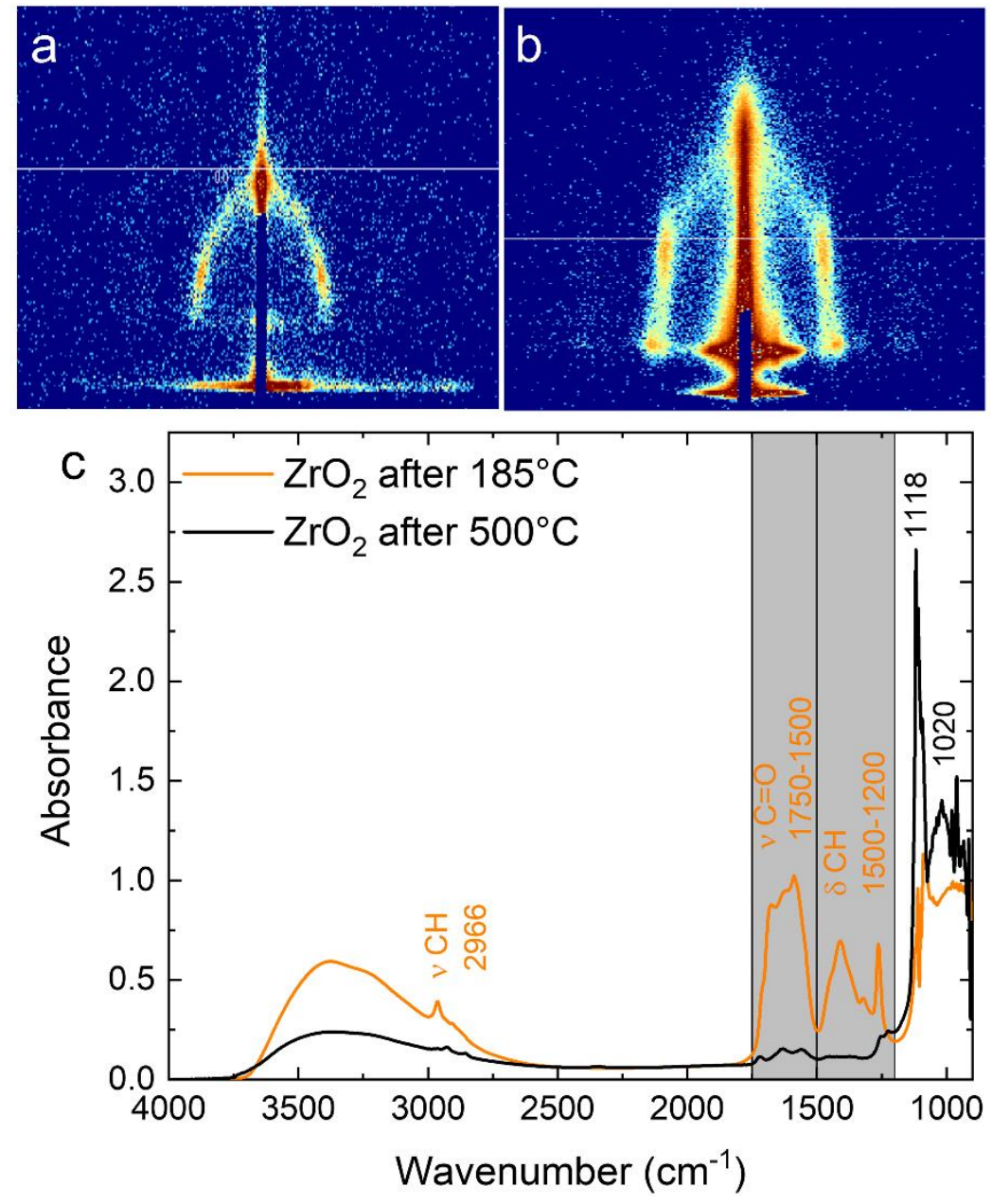

Figure 3. GI-SAXS patterns of cubic mesoporous $\mathrm{ZrO}_{2}$ coatings. (a) after the aging process and (b) after calcination at $500{ }^{\circ} \mathrm{C}$. (c) FT-IR absorbance spectra of the mesoporous $\mathrm{ZrO}_{2}$ coating with band assignments after the aging process and after calcination at $500{ }^{\circ} \mathrm{C}$. 


\section{Chemical Stability of Mesoporous Zirconia}

The chemical stability of the mesoporous $\mathrm{ZrO}_{2}$ coating compared to an unfunctionalized mesoporous $\mathrm{SiO}_{2}$ coating was investigated. According to the literature, $\mathrm{SiO}_{2}$ is stable at $\mathrm{pH}$ values below 8 , while $\mathrm{ZrO}_{2}$ is chemically inert between $\mathrm{pH}=1$ and 14 . $^{21,32}$ To broaden the range of applications for sensing in aqueous media for $\mathrm{pH}>7$, the chemical stability in alkaline solution was investigated. Both coatings were placed in a flask filled with $0.01 \mathrm{M} \mathrm{NaOH}$ solution with a $\mathrm{pH}$ value of 12. Microscopic images showed the complete removal of the mesoporous $\mathrm{SiO}_{2}$ coating after $12 \mathrm{~h}$ (Fig. S7, Supplemental Material). However, even after $72 \mathrm{~h}$ in this solution, the mesoporous $\mathrm{ZrO}_{2}$ coating remained present, but with a change in color. Small-angle XRD patterns confirmed the presence of the mesostructure with a contraction of $10 \%$ and the FT-IR spectra only showed minor differences, as seen in Fig. 4.
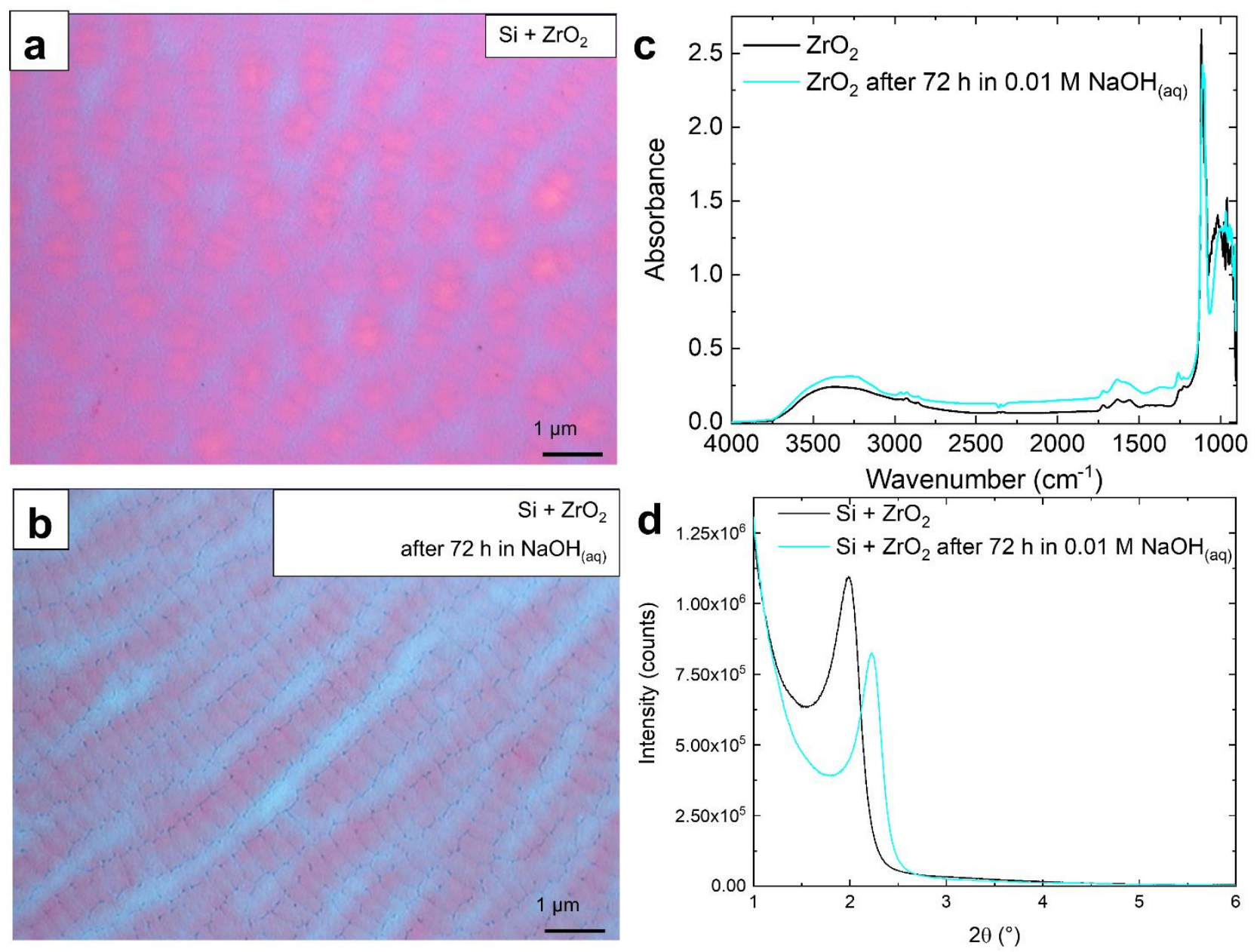

Figure 4. Microscopic images of $\mathrm{ZrO}_{2}$-coated Si ATR crystals (a) before and (b) after placing the coating in the $0.01 \mathrm{M} \mathrm{NaOH}$ solution. (c) XRD patterns and (d) FT-IR absorbance spectra before and after placing the coating in the $0.01 \mathrm{M} \mathrm{NaOH}$ solution. 


\section{Surface Modification Using Silanes}

The surface of a mesoporous $\mathrm{ZrO}_{2}$ coating was modified using trichloro(phenyl)silane. The successful functionalization and increase in hydrophobicity were characterized using static contact angle measurements. The obtained contact angles were $25.0^{\circ}$ and $71.8^{\circ}$ for the pristine and modified $\mathrm{ZrO}_{2}$ coating, respectively. Additionally, bands of the $\mathrm{C}-\mathrm{H}$ stretching vibration between $3100 \mathrm{~cm}^{-1}$ and $2800 \mathrm{~cm}^{-1}$ as well as at approx. $1250 \mathrm{~cm}^{-1}$ confirm the presence of organic moieties. ${ }^{24}$ Bands at $1595 \mathrm{~cm}^{-1}$ and $1430 \mathrm{~cm}^{-1}$ are characteristic of $\mathrm{C}=\mathrm{C}$ stretching vibrations of the benzene ring and in-plane hydrogen bending, respectively. ${ }^{33,34}$ The hydrophobicity was further confirmed with FT-IR spectra of water on uncoated and coated Si ATR crystals. The IR bands associated with vibrations of $\mathrm{H}_{2} \mathrm{O}$ are less intense for the modified coating compared to blank Si-ATR crystals, as seen in Figure 5. The refractive index of the modified $\mathrm{ZrO}_{2}$ film was determined using mid-IR ellipsometry to be $\mathrm{n}=1.72$ at $2300 \mathrm{~cm}^{-1}$ by extracting it from the measurement of the combined $\mathrm{Si} / \mathrm{ZrO}_{2}$ stack (see Fig. S8, Supplemental Material). This value is approx. $15 \%$ lower compared to dense $\mathrm{ZrO}_{2}$, due to a porosity of approx. $30 \%$ of the mesoporous film.
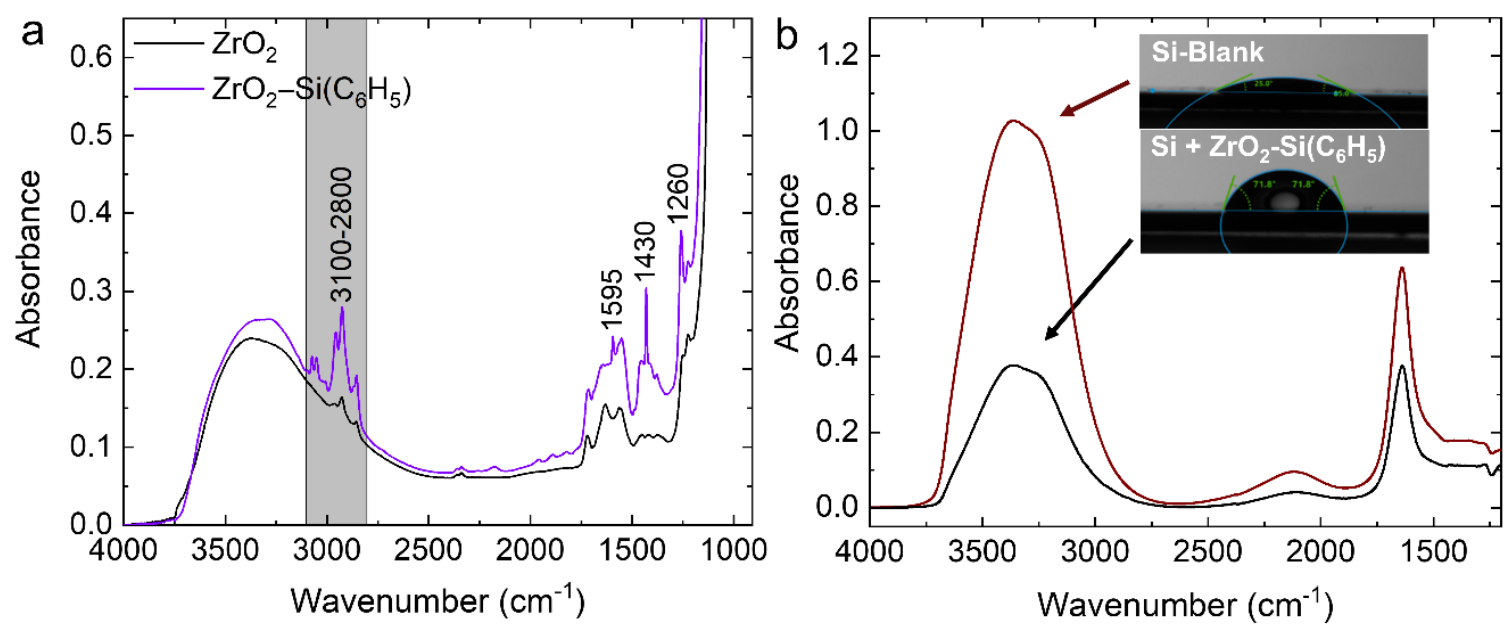

Figure 5. (a) FT-IR absorbance spectra of $\mathrm{ZrO}_{2}$-coated Si ATR crystals before and after surface modification. (b) FT-IR absorbance spectra of water on an uncoated and $\mathrm{ZrO}_{2}$-coated Si ATR crystal after surface modification. 


\section{Adsorption/Desorption Studies of Benzonitrile Solutions}

Analyte solutions were applied using stainless-steel tubing attached to the flow cell and a peristaltic pump. The speed of adsorption and desorption of benzonitrile was investigated by applying water, $100 \mathrm{mg} \mathrm{L}^{-1}$ benzonitrile in water, and water, consecutively, while collecting FT-IR spectra averaged over 16 scans, resulting in a measuring time of $4 \mathrm{~s}$ for each spectrum. For evaluation, the band area of the $\mathrm{CN}$ vibration was calculated and displayed in a timeline. Fig. $6 \mathrm{~b}$ shows that it requires $32 \mathrm{~s}$ to reach $90 \%$ of the maximum IR absorbance during the adsorption and approx. $28 \mathrm{~s}$ to reach $10 \%$ of the maximum IR absorbance during the desorption process. Varying the flow rate between $0.5 \mathrm{~mL} \mathrm{~min}^{-1}$ and $2.0 \mathrm{~mL} \mathrm{~min}^{-1}$ had little effect on the maximum absorption after equilibration (Fig. S9, Supplemental Material).
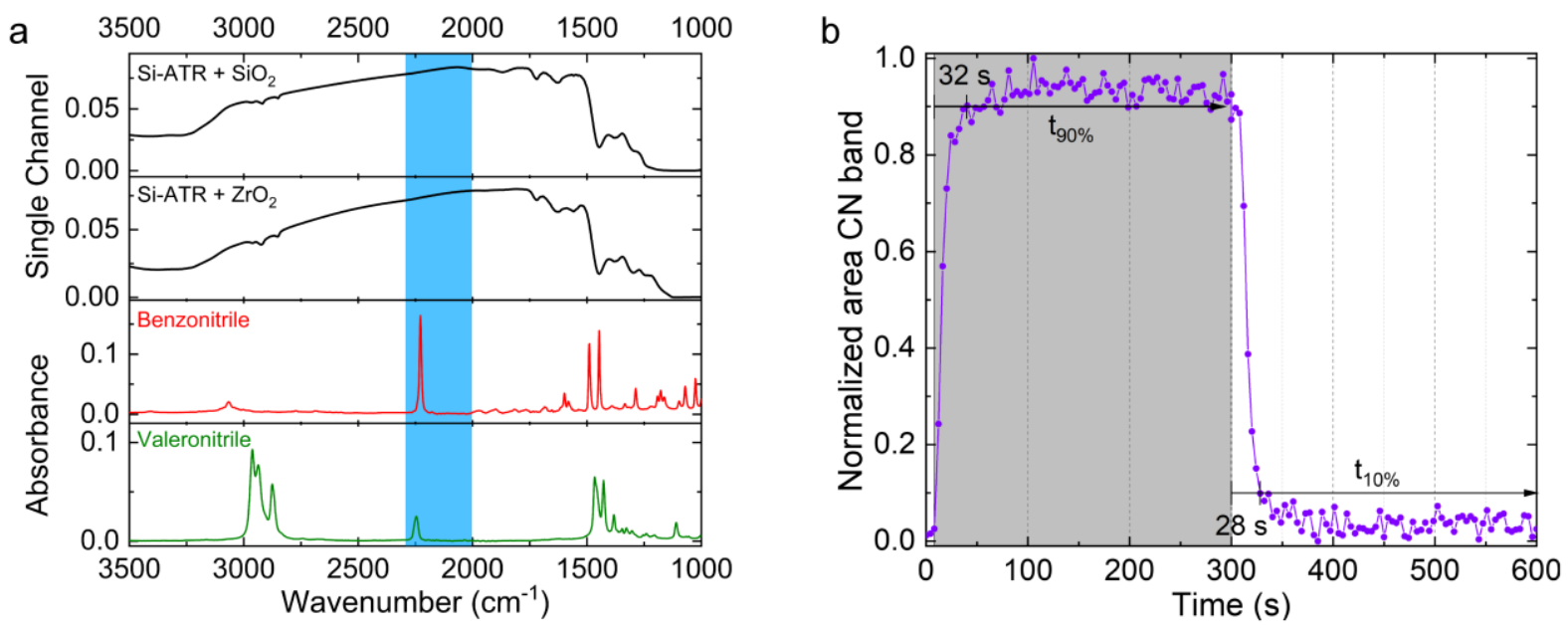

Figure 6. (a) Single channel spectra of $\mathrm{Si}$ ATR crystals coated with $\mathrm{SiO}_{2}$ and $\mathrm{ZrO}_{2}$. The maximum transmission of the Si ATR spectrum is highlighted in dark blue. ATR-FTIR spectra of pure benzonitrile and pure valeronitrile with the evaluated $v-\mathrm{CN}$ at approx. $2250 \mathrm{~cm}^{-1}$. (b) Adsorption and desorption profile of $100 \mathrm{mg} \mathrm{L}^{-1}$ benzonitrile in water onto modified

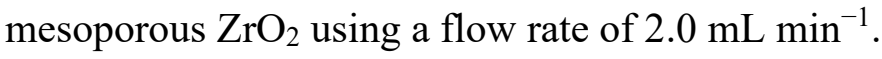




\section{Equilibrium Adsorption Experiments}

For equilibrium adsorption experiments, benzonitrile and valeronitrile were used as model analytes. Fig. 6a shows ATR-IR spectra of the pure compounds. Aqueous solutions of the model compounds with concentrations ranging from $10 \mathrm{mg} \mathrm{L}^{-1}$ to $200 \mathrm{mg} \mathrm{L}^{-1}$ were applied to the modified $\mathrm{ZrO}_{2}$ coating until the maximum absorbance was reached. The band areas were calculated after baseline subtraction and are displayed for both benzonitrile and valeronitrile in Figure 7A. The data was fitted using Langmuir and Freundlich isotherms. ${ }^{13}$ The models are expressed by the following equations:

$$
\begin{aligned}
& \text { Langmuir isotherm: } q_{e}=\frac{q_{m} K_{L} c}{1+K_{L} c} \\
& \text { Freundlich isotherm: } q_{e}=K_{F} c^{\frac{1}{n}}
\end{aligned}
$$

where $q_{e}$ is the amount of adsorbed analyte $\left(\mathrm{cm}^{-1}\right.$ or $\left.\mathrm{mg} \mathrm{cm}^{-3}\right), q_{m}$ is the maximum adsorption capacity $\left(\mathrm{cm}^{-1}\right.$ or $\left.\mathrm{mg} \mathrm{cm}^{-3}\right), K_{\mathrm{L}}$ is the Langmuir constant $\left(\mathrm{L} \mathrm{mg}^{-1}\right), c$ is the concentration of the analyte in solution $\left(\mathrm{mg} \mathrm{L}^{-1}\right), K_{F}$ is the Freundlich constant $\left(\mathrm{AU} \mathrm{cm}{ }^{-3}[\mathrm{~L} \mathrm{mg}]^{1 / n}\right.$ or $\mathrm{mg} \mathrm{cm}{ }^{-3}[\mathrm{~L} \mathrm{mg}]^{1 / n}$ ), and $n$ is the Freundlich linearity index. The Freundlich fit showed lower $\chi^{2}$ values, indicating a better fit for this model. ${ }^{35}$ The calculated $\chi^{2}$ values for both models and the Freundlich parameters are summarized in Table I. As shown in our previous study on mesoporous silica, the fit for the Freundlich adsorption shows a lower $\chi^{2}$ and thus a better fit, which indicates multi-layer adsorption at the pore surface.

Table I. Calculated isotherm parameters for the calibration curves of benzonitrile and valeronitrile.

$\begin{array}{ccccc}\text { Analyte } & \chi_{F}^{2 a} & \chi_{L}^{2 b} & \mathrm{~K}^{c} & n^{d} \\ & & & \left(\mathrm{AU} \mathrm{cm}{ }^{-1}[\mathrm{~L} \mathrm{mg}]^{1 / n}\right) & \\ \text { Benzonitrile } & 2.010^{-4} & 1.610^{-3} & 2.910^{-3} & 1.35 \\ \text { Valeronitrile } & 4.210^{-4} & 5.510^{-4} & 3.910^{-4} & 1.18\end{array}$

${ }^{\mathrm{a}}$ Freundlich fit $\chi^{2}$ value. ${ }^{\mathrm{b}}$ Langmuir fit $\chi^{2}$ value. ${ }^{\mathrm{c}}$ Freundlich constant. ${ }^{\mathrm{d}}$ Freundlich linearity index. 

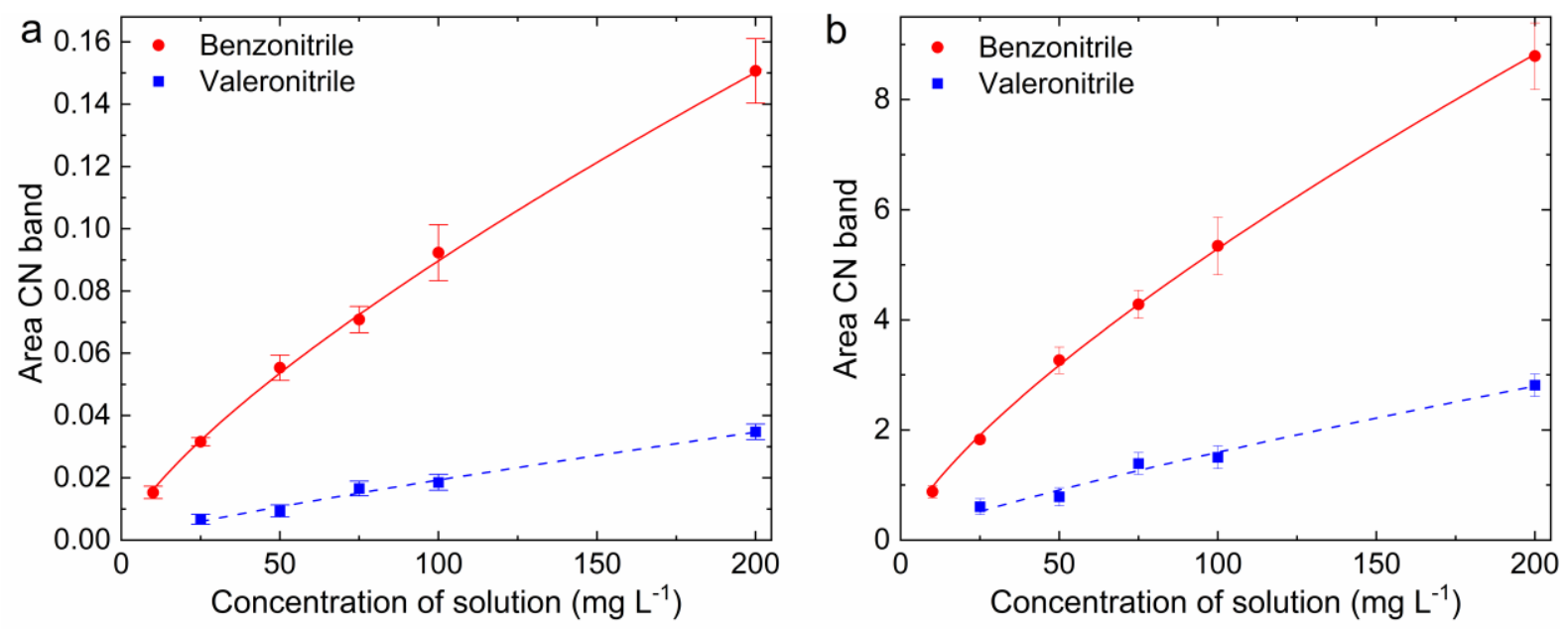

Figure 7. (a) Calibration curves for the enrichment fitted with the Freundlich model and (b) adsorption isotherms obtained from the Beer-Lambert law of benzonitrile and valeronitrile solutions using the modified $\mathrm{ZrO}_{2}$ coating

\section{Translation of Infrared Absorbance to Absolute Concentrations}

The theoretical considerations for the translation from IR absorbance to absolute concentrations have already been established. ${ }^{13}$ In short, the effective path length $d_{e}$, which is defined as the identical IR absorbance that would be obtained from transmission measurements with the same path length and can be used for quantitative analysis, is scaled by the fraction of the evanescent field within the film to yield $\mathrm{d}_{\mathrm{e}, \text { film }} \cdot{ }^{13,36}$ For the given film thickness of $t h=237 \mathrm{~nm}$, a fraction of the evanescent wave within the film of $s=0.67$ was derived. With the refractive indices of the coating $\left(n_{1}=1.72\right.$, see Fig. S8 for refractive index spectrum of $\left.\mathrm{ZrO}_{2}\right)$ and the Si ATR crystal $\left(n_{2}=3.42\right)$, the angle of incidence $\left(\theta=45^{\circ}\right)$, number of active bounces $\mathrm{N}=19$ and the wavelength $\left(\lambda_{0}=4.45 \mu \mathrm{m}, \mathrm{v}=2247 \mathrm{~cm}^{-1}\right.$ band position of $\left.v-\mathrm{CN}\right)$, a depth of penetration $d_{\mathrm{p}}$ of $0.423 \mu \mathrm{m}$ and an $\mathrm{N} \times d_{\mathrm{e}, \text { film }}$ of $19 \times 0.661 \mu \mathrm{m}=7.82 \mu \mathrm{m}$ are obtained.

The insertion of $d_{e, f i m}$ into Beer-Lambert's law allows to retrieve absolute analyte concentrations: $A=c \times d_{e, f i l m} \times \varepsilon \times N$. Note that the thereby obtained analyte concentrations are given in the unit mass per film volume $\left(\mathrm{mg} \mathrm{cm}^{-3}\right.$, see Fig. $\left.7 \mathrm{~b}\right)$, which allows to directly compare the obtained absorption capacities with other typically employed gravimetric techniques. ${ }^{13}$ Furthermore, the absolute mass of adsorbed analyte can be determined from the adsorbed nitrile concentration as the volume of the film is known by the film thickness and the size of the ATR crystal's surface, resulting in a volume of $4.7 \times 10^{-5} \mathrm{~cm}^{3}$. Applying these considerations to the absorbance values obtained from the nitrile adsorption, absolute nitrile 
masses of $0.25 \mu \mathrm{g}$ and $0.07 \mu \mathrm{g}$ analyte were adsorbed in the coating from $100 \mathrm{mg} \mathrm{L}^{-1}$ solutions of benzonitrile and valeronitrile, respectively. We denote the higher enrichment of benzonitrile compared to valeronitrile to the higher solubility of valeronitrile in water and hence lower affinity towards the apolar surface. ${ }^{37}$

Figures of Merit of the Sensing System

With the previously obtained parameters, the limit-of-detection (LOD), defined as $\mathrm{q}_{\mathrm{e}}(\mathrm{LOD})=3 \times \sigma$, with $\sigma$ being the standard deviation derived from consecutive $100 \%$ lines, ${ }^{13}$ and the enrichment factors were derived. With the parameters of the Freundlich isotherms in Table I and the noise floor of the measured signal of $10^{-3} \mathrm{~cm}^{-1}$, LODs of $1.0 \mathrm{mg} \mathrm{L}^{-1}$ and $11 \mathrm{mg} \mathrm{L}^{-1}$ were obtained for benzonitrile and valeronitrile, respectively, which are close the LODs obtained from mesoporous silica films of 1.5 and $6.6 \mathrm{mg} \mathrm{L}^{-1}$. Enrichment factors are calculated from the ratio of adsorbed analyte in the coating and the solution. For benzonitrile, an enrichment factor of 162 was calculated for the $10 \mathrm{mg} \mathrm{L}^{-1}$ solution, whereas an enrichment factor of 26 was obtained for the $25 \mathrm{mg} \mathrm{L}^{-1}$ solution of valeronitrile. Therefore, the phenylmodified $\mathrm{ZrO}_{2}$ coating shows a higher enrichment for the aromatic nitrile. In comparison to the trimethyl-silane-modified mesoporous silica films of our previous study, the enrichment factor of valeronitrile is 4-times smaller. We attribute this reduction to a decrease in affinity of the aliphatic analyte towards the phenyl-modified $\mathrm{ZrO}_{2}$ and the higher solubility of valeronitrile in water. In addition, we find the same fast response time of $<5 \mathrm{~s}$ as we reported for the mesoporous silica film which can be ascribed to the high porosity and hence ease of diffusion of the analytes into the enrichment film. 


\section{Conclusion}

In this work, we present the synthesis and thorough characterization of mesoporous zirconia coatings combined with IR spectroscopy. The high thermal stability and strong chemical resistance to alkaline solutions was demonstrated using XRD and FT-IR spectroscopy. Application of this coating as enrichment layers on ATR crystals allow in situ monitoring of adsorption/desorption processes using ATR FT-IR spectroscopy. This technique allows to directly access qualitative and quantitative information of the analyte molecules. The broad range of commercially available silanes allows for a wide range of possible surface modifications, which can be used to direct the selectivity towards specific analytes. In this work, the surface of the mesoporous zirconia layer was modified with phenyl moieties for increased sensitivity to aromatic and aliphatic analytes. Benzonitrile and valeronitrile in water were used as model analytes to evaluate the enrichment performance of the film. Even though only small film thicknesses were obtained after calcination, there could be obtained very high enrichment factors for benzonitrile (162) and moderate enrichment factors for valeronitrile (26).

Alternatively, also the pristine zirconia layer can be employed for enrichment of ionic species. In this context, a cationic species of interest is $\mathrm{CTAB}$, which is a frequently used corrosion inhibitor of steel and therefore of great importance in chemical industry. Anionic species that are in the focus of our future research include sulfates and phosphates. Removal of phosphate from wastewater is in the general focus of research due to its contribution to eutrophication. For both of these anionic analytes, the characteristic IR absorption bands are located at approx. $1200 \mathrm{~cm}^{-1}$, so for these applications, the use of mesoporous zirconia enrichment layers is highly beneficial as opposed to e.g. mesoporous silica layers due to higher spectral accessibility in the low wavenumber region. 


\section{Acknowledgements}

We acknowledge the CzechNanoLab Research Infrastructure supported by MEYS CR (LM2018110) for the expert technical assistance. Si wafers were provided by the IMEC research group at Ghent University. Si-ATR crystals were prepared at the USTEM sample preparation laboratory at TU Wien. X-ray diffraction measurements were performed at the XRC at TU Wien.

\section{Declaration of Conflicting Interests}

The author(s) declared no potential conflicts of interest with respect to the research, authorship, and/or publication of this article.

\section{Funding}

This work is part of the HYDROPTICS project, which has received funding from the European Union's Horizon 2020 research and innovation program under the grant agreement No. 871529. This project is an initiative of the Photonics Public Private Partnership. Parts of this work was supported by the Austrian Science Fund (FWF) Meitner Program (M2485-N34). Further financial support has been received from the COMET Center CHASE (project No 868615), which is funded within the framework of COMET (Competence Centers for Excellent Technologies) by BMVIT, BMDW, and the Federal Provinces of Upper Austria and Vienna. The COMET program is run by the Austrian Research Promotion Agency (FFG).

\section{Supplemental Material}

All supplemental material mentioned in the text, consisting of figures, is available in the online version of the journal. 


\section{References}

1. M. Lamotte, P.F. de Violet, P. Garrigues, M. Hardy. "Evaluation of the Possibility of Detecting Benzenic Pollutants by Direct Spectrophotometry on Pdms Solid Absorbent". Anal. Bioanal. Chem. 2002. 372(1): 169-173.

2. R. Lu, G.P. Sheng, W.W. Li, H.Q. Yu, Y. Raichlin, A. Katzir, B. Mizaikoff. "Ir-Atr Chemical Sensors Based on Planar Silver Halide Waveguides Coated with an Ethylene/Propylene Copolymer for Detection of Multiple Organic Contaminants in Water". Angew. Chem. Int. Edit. 2013. 52(8): 2265-2268.

3. R. Stach, B. Pejcic, E. Crooke, M. Myers, B. Mizaikoff. "Mid-Infrared Spectroscopic Method for the Identification and Quantification of Dissolved Oil Components in Marine Environments". Anal. Chem. 2015. 87(24): 12306-12312.

4. P. Heinrich, R. Wyzgol, B. Schrader, A. Hatzilazaru, D.W. Lubbers. "Determination of Organic-Compounds by Ir/Atr Spectroscopy with Polymer-Coated Internal-Reflection Elements". Appl Spectrosc 1990. 44(10): 1641-1646.

5. R. Krska, K. Taga, R. Kellner, A. Messica, A. Katzir. "A New Fiber Optic Physicochemical Sensor for Chlorinated Hydrocarbons in Water". Fresen J Anal Chem 1992. 342(1-2): 202-202.

6. R. Krska, K. Taga, R. Kellner. "New Ir Fiberoptic Chemical Sensor for in-Situ Measurements of Chlorinated Hydrocarbons in Water". Appl Spectrosc 1993. 47(9): 1484-1487.

7. R. Kellner, R. Gobel, R. Gotz, B. Lendl, B. Edlmizaikoff, M. Tacke, A. Katzir. "Recent Progress on Mid-Ir Sensing with Optical Fibers". P Soc Photo-Opt Ins 1995. 2508: 212223.

8. M. Grahn, A. Holmgren, J. Hedlund. "Adsorption of N-Hexane and P-Xylene in Thin Silicalite-1 Films Studied by Ftir/Atr Spectroscopy". J. Phys. Chem. C 2008. 112(20): 7717-7724.

9. Z. Wang, M.L. Larsson, M. Grahn, A. Holmgren, J. Hedlund. "Zeolite Coated Atr Crystals for New Applications in Ftir-Atr Spectroscopy". Chem. Commun. 2004. (24): 2888-2889.

10. G.G. Huang, C.T. Wang, H.T. Tang, Y.S. Huang, J. Yang. "Zno Nanoparticle-Modified Infrared Internal Reflection Elements for Selective Detection of Volatile Organic Compounds". Anal. Chem. 2006. 78(7): 2397-2404.

11. M. Janotta, A. Katzir, B. Mizaikoff. "Sol-Gel-Coated Mid-Infrared Fiber-Optic Sensors". Appl Spectrosc 2003. 57(7): 823-828.

12. B. Baumgartner, J. Hayden, B. Lendl. "Mesoporous Silica Films for Sensing Volatile Organic Compounds Using Attenuated Total Reflection Spectroscopy". Sensor. Actuat. B-Chem. 2020. 302: 127194.

13. B. Baumgartner, J. Hayden, A. Schwaighofer, B. Lendl. "In Situ Ir Spectroscopy of Mesoporous Silica Films for Monitoring Adsorption Processes and Trace Analysis". ACS Appl. Nano Mater. 2018. 1(12): 7083-7091.

14. Y.F. Lu, L. Han, C.J. Brinker, T.M. Niemczyk, G.P. Lopez. "Chemical Sensors Based on Hydrophobic Porous Sol-Gel Films and Atr-Ftir Spectroscopy". Sensor. Actuat. BChem. 1996. 36(1-3): 517-521. 
15. L. Bourda, H.S. Jena, R. Van Deun, A.M. Kaczmarek, P. Van der Voort. "Functionalized Periodic Mesoporous Organosilicas: From Metal Free Catalysis to Sensing". J. Mater. Chem. A 2019. 7(23): 14060-14069.

16. L.T. Gibson. "Mesosilica Materials and Organic Pollutant Adsorption: Part a Removal from Air". Chem. Soc. Rev. 2014. 43(15): 5163-5172.

17. Q. Zheng, Y.H. Zhu, J.Q. Xu, Z.X. Cheng, H.M. Li, X.X. Li. "Fluoroalcohol and Fluorinated-Phenol Derivatives Functionalized Mesoporous Sba-15 Hybrids: HighPerformance Gas Sensing toward Nerve Agent". J. Mater. Chem. 2012. 22(5): 22632270 .

18. G.J.D.A. Soler-Illia, A. Louis, C. Sanchez. "Synthesis and Characterization of Mesostructured Titania-Based Materials through Evaporation-Induced Self-Assembly". Chem. Mater. 2002. 14(2): 750-759.

19. G.J.A.A. Soler-Illia, P.C. Angelome, M.C. Fuertes, A. Calvo, A. Wolosiuk, A. Zelcer, M.G. Bellino, E.D. Martinez. "Mesoporous Hybrid and Nanocomposite Thin Films. A Sol-Gel Toolbox to Create Nanoconfined Systems with Localized Chemical Properties". J. Sol-Gel Sci. Technol. 2011. 57(3): 299-312.

20. P. Innocenzi, L. Malfatti. "Mesoporous Thin Films: Properties and Applications". Chem. Soc. Rev. 2013. 42(9): 4198-4216.

21. M. Kawahara, H. Nakamura, T. Nakajima. "Titania and Zirconia - Possible New Ceramic Microparticulates for High-Performance Liquid-Chromatography". J. Chromatogr. 1990. 515: 149-158.

22. A. Wehrli, J.C. Hildenbrand, H.P. Keller, R. Stampfli, R.W. Frei. "Influence of Organic-Bases on Stability and Separation Properties of Reversed-Phase Chemically Bonded Silica-Gels". J. Chromatogr. 1978. 149(Feb): 199-210.

23. D.R. Dunphy, S. Singer, A.W. Cook, B. Smarsly, D.A. Doshi, C.J. Brinker. "Aqueous Stability of Mesoporous Silica Films Doped or Grafted with Aluminum Oxide". Langmuir 2003. 19(24): 10403-10408.

24. G. Socrates. Infrared and Raman Characteristic Group Frequencies : Tables and Charts. Chichester ; New York: Wiley, 1994. 2nd ed.

25. U. Trudinger, G. Muller, K.K. Unger. "Porous Zirconia and Titania as Packing Materials for High-Performance Liquid-Chromatography". J. Chromatogr. 1990. 535(12): 111-125.

26. J. Nawrocki, M.P. Rigney, A. Mccormick, P.W. Carr. "Chemistry of Zirconia and Its Use in Chromatography". J. Chromatogr. A 1993. 657(2): 229-282.

27. K.X. Wang, M.A. Morris, J.D. Holmes, J.H. Yu, R.R. Xu. "Thermally Stable Nanocrystallised Mesoporous Zirconia Thin Films". Micropor. Mesopor. Mat. 2009. 117(1-2): 161-164.

28. J. Kujawa, S. Cerneaux, W. Kujawski. "Removal of Hazardous Volatile Organic Compounds from Water by Vacuum Pervaporation with Hydrophobic Ceramic Membranes". J. Membrane Sci. 2015. 474: 11-19.

29. J. Kujawa, W. Kujawski, A. Cyganiuk, L.F. Dumee, S. Al-Gharabli. "Upgrading of Zirconia Membrane Performance in Removal of Hazardous Vocs from Water by Surface Functionalization". Chem. Eng. J. 2019. 374: 155-169. 
30. N. Nishiyama, S. Tanaka, Y. Egashira, Y. Oku, K. Ueyama. "Enhancement of Structural Stability of Mesoporous Silica Thin Films Prepared by Spin-Coating". Chem. Mater. 2002. 14(10): 4229-4234.

31. B. Baumgartner, Doctoral, TU Wien, Vienna (2019).

32. M.P. Rigney, E.F. Funkenbusch, P.W. Carr. "Physical and Chemical Characterization of Microporous Zirconia". J. Chromatogr. 1990. 499: 291-304.

33. A.L. Smith. "Vibrational Spectra and Assignments for Phenyl Chlorosilanes". Spectrochim. Acta, Part A 1967. A 23(4): 1075-1087.

34. D.H. Whiffen. "Vibrational Frequencies and Thermodynamic Properties of FluoroBenzene, Chloro-Benzene, Bromo-Benzene, and Iodo-Benzene". J. Chem. Soc. 1956. (Jun): 1350-1356.

35. Y.S. Ho. "Selection of Optimum Sorption Isotherm". Carbon 2004. 42(10): 2115-2116.

36. G. Ramer, B. Lendl. "Attenuated Total Reflection Fourier Transform Infrared Spectroscopy". Encyclopedia of Analytical Chemistry. Hoboken, NJ, USA: John Wiley \& Sons, Ltd, 2013.

37. Institut für Arbeitsschutz der Deutschen Gesetzlichen Unfallversicherung (IFA). "GESTIS Substance Database". 2021. https://gestis-database.dguv.de/ [last accessed: 15.09.2021]. 